\title{
1 Visually Induced Changes in Cytokine Production in the Chick \\ 2 \\ Choroid
}

\author{
Jody A. Summers ${ }^{a}$ and Elizabeth Martinez Cano ${ }^{a}$,
}

aDepartment of Cell Biology, University of Oklahoma Health Sciences Center, Oklahoma City, Oklahoma, 73104, United States

Email Addresses: Jody Summers: jody-summers@ouhsc.edu

Elizabeth Martinez Cano: Elizabeth-MartinezCano@ouhsc.edu 


\section{ABSTRACT}

15 Postnatal ocular growth is regulated by a vision-dependent mechanism which acts to minimize

16 refractive error through coordinated growth of the ocular tissues. Of great interest is the

17 identification of the chemical signals that control visually-guided ocular growth. Here we provide

18 evidence that the pro-inflammatory cytokine, Interleukin-6 (IL-6), may play a pivotal role in the

19 control of ocular growth using a chicken model of myopia. Microarray, real time RT-qPCR, and

20 ELISA analyses identified IL-6 upregulation in the choroids of chick eyes under two visual

21 conditions that introduce myopic defocus and slow the rate of ocular elongation (recovery from

22 induced myopia and compensation for positive lenses). Intraocular administration of atropine,

23 an agent known to slow ocular elongation, also resulted in an increase in choroidal IL-6 gene

24 expression. Nitric oxide appears to directly or indirectly upregulate choroidal IL-6 gene

25 expression, as administration of the non-specific nitric oxide synthase inhibitor, L-NAME,

26 inhibited choroidal IL-6 gene expression, and application of a nitric oxide donor stimulated IL-6

27 gene and protein expression in isolated chick choroids. Considering the pleiotropic nature of IL-

286 and involvement in many biological processes, these results suggest that IL-6 may mediate

29 many aspects of the choroidal response in the control of ocular growth. 


\section{Introduction}

High myopia is a significant risk factor for several blinding eye diseases including glaucoma,

37 retinal detachment and macular degeneration, and therefore represents a leading cause of blindness worldwide (Buch, Vinding et al., 2001). The prevalence of myopia is continuing to increase and is expected to affect nearly half of the global population by 2050 (Holden, Fricke et al., 2016). Although clinical and experimental studies indicate that normal eye growth

41 (emmetropization) is controlled by visual input (Wallman \& Winawer, 2004), the cause of myopia

42 in humans is not understood.

Animal models have provided valuable insights into the role of the visual environment on

44 ocular growth control. Deprivation of form vision, through the use of visual "occluders" or

45 "goggles" results in accelerated ocular growth and the development of myopia within a matter of

46 days in chicks, tree shrews, guinea pigs, and primates (Howlett \& McFadden, 2006, Sherman,

47 Norton et al., 1977, Troilo \& Judge, 1993, Wallman, Turkel et al., 1978). Upon removal of the

48 occluder, normal visual input is restored to the elongated myopic eye, resulting in a rapid

49 deceleration in ocular elongation and eventual return to emmetropia ("recovery") (Wallman \&

50 Adams, 1987).

Postnatal ocular growth can also be manipulated through the application of positive or

52 negative lenses, as the eye has been shown to compensate for the imposed defocus in many

53 vertebrates, including fish, chicks, mammals, and primates (Graham \& Judge, 1999, Hung,

54 Crawford et al., 1995, Norton, Siegwart et al., 2006, Schaeffel, Glasser et al., 1988, Shen \& Sivak,

55 2007). Application of positive lenses, which cause images to form in front of the retina (myopic

56 defocus), results in slowing the rate of ocular elongation and thickening of the choroid, in order 
57 to push the retina toward the image plane (Wallman, Wildsoet et al., 1995). Conversely,

58 application of negative lenses results in an increased rate of elongation and thinning the choroid

59 to pull the retina back toward the image plane.

60 It is well-established that visually induced changes in ocular length are the result of a locally

61 driven "retina-to-choroid-to-scleral chemical signaling cascade" that is initiated by a visual

62 stimulus, followed by chemical changes in the retina and choroid, ultimately resulting in altered

63 extracellular matrix (ECM) remodeling of the scleral shell (Troilo, Smith et al., 2019). The choroid,

64 a highly vascularized layer located immediately adjacent to the sclera, has been shown to

65 undergo changes in thickness, permeability and blood flow during periods of visually guided eye

66 growth (Fitzgerald, Wildsoet et al., 2002, Pendrak, Papastergiou et al., 2000, Rada \& Palmer,

67 2007, Wallman et al., 1995). Moreover, due its proximity to the sclera, the choroid is suspected

68 to synthesize and/or release scleral growth regulators to control the rate of ocular elongation in

69 response to visual stimuli (Marzani \& Wallman, 1997, Rada \& Palmer, 2007). All-trans-retinoic

70 acid is one potential choroidally-derived scleral growth regulator, whose choroidal

71 concentrations are modulated by the activity of retinaldehyde dehydrogenase 2 (RALDH2)(Mertz

72 \& Wallman, 2000, Rada, 2012). Of much interest, therefore, are the identification of genes

73 causally involved in the regulation of the choroidal response during visually guided eye growth.

74 Here, we report rapid and significant changes in choroidal gene expression of the pluripotent

75 cytokine, interleukin 6 (IL-6), in response to myopic defocus and in response to chemical

76 treatments known to modulate eye growth. Considering the pleiotropic nature of IL-6 and

77 involvement in many biological processes, these results suggest that IL-6 may mediate many 
78 aspects of the choroidal response in the control of ocular growth. A preliminary report of our

79 findings was presented previously (Summers and Martinez, IOVS 2020 61: E-abstract 3400).

\section{Results}

\section{Expression of IL-6 in chick ocular tissues}

82 Immunohistochemical staining for IL-6 indicated that IL-6 is expressed in numerous cells

83 throughout the choroid and RPE as punctate cytoplasmic deposits (Figure 1A,B). IL-6-containing

84 cells included the RPE, choroidal endothelial cells (blood vessels are labelled with asterisks), and

85 choroidal stromal cells. Immunolabelling was abolished after incubation of this antibody with a

86 10-fold molar excess of chicken IL-6 demonstrating that the immunohistochemical detection

87 procedure was specific (Figure 1C).

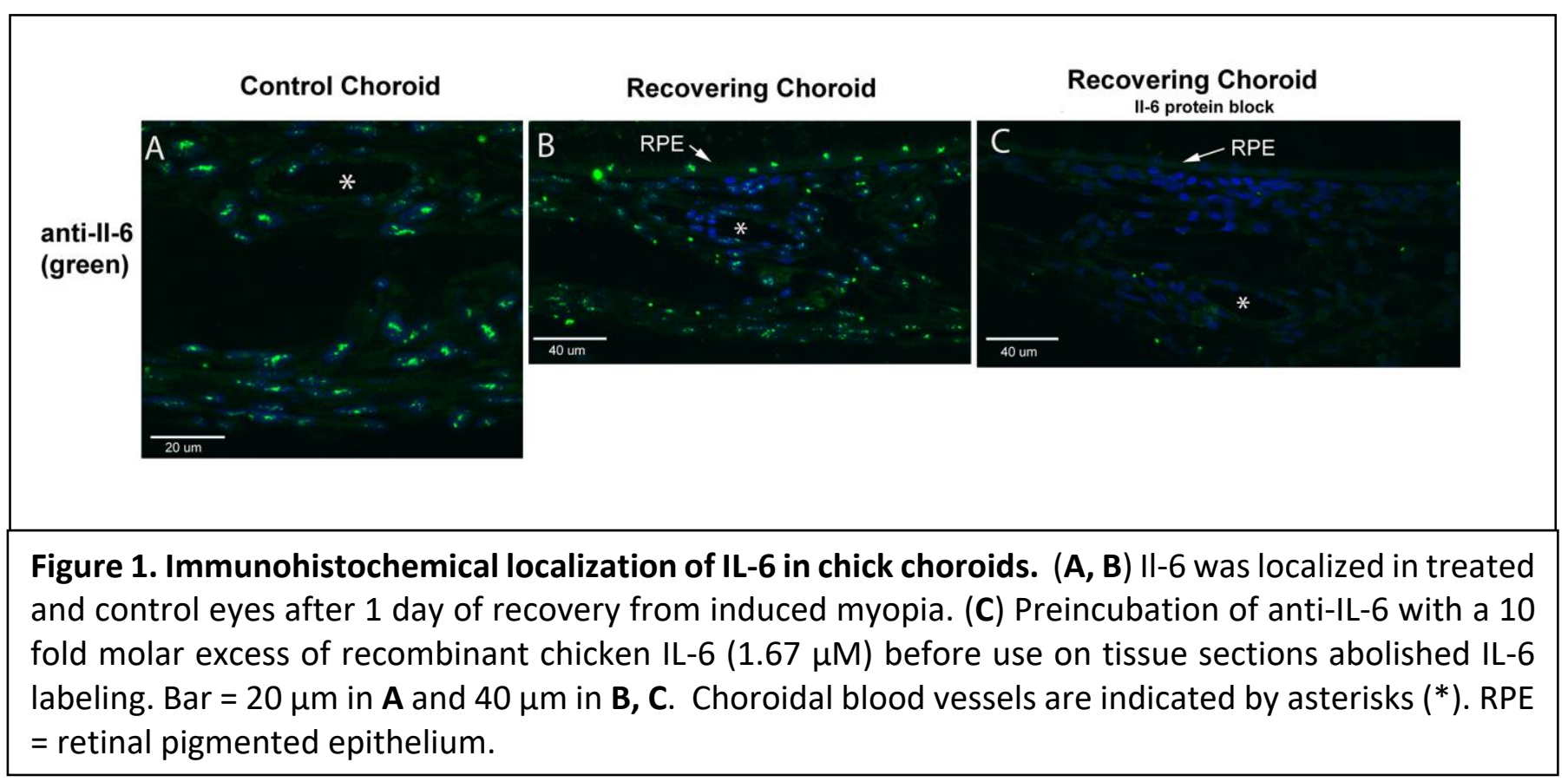


91 Form Deprivation and Recovery. Preliminary results from an Affymetrix microarray experiment

92 indicated that IL-6 was increased over 10 fold in choroids of chick eyes following 6 hrs of recovery,

93 compared with normal, untreated eyes (Figure 2).

94

95

96

97

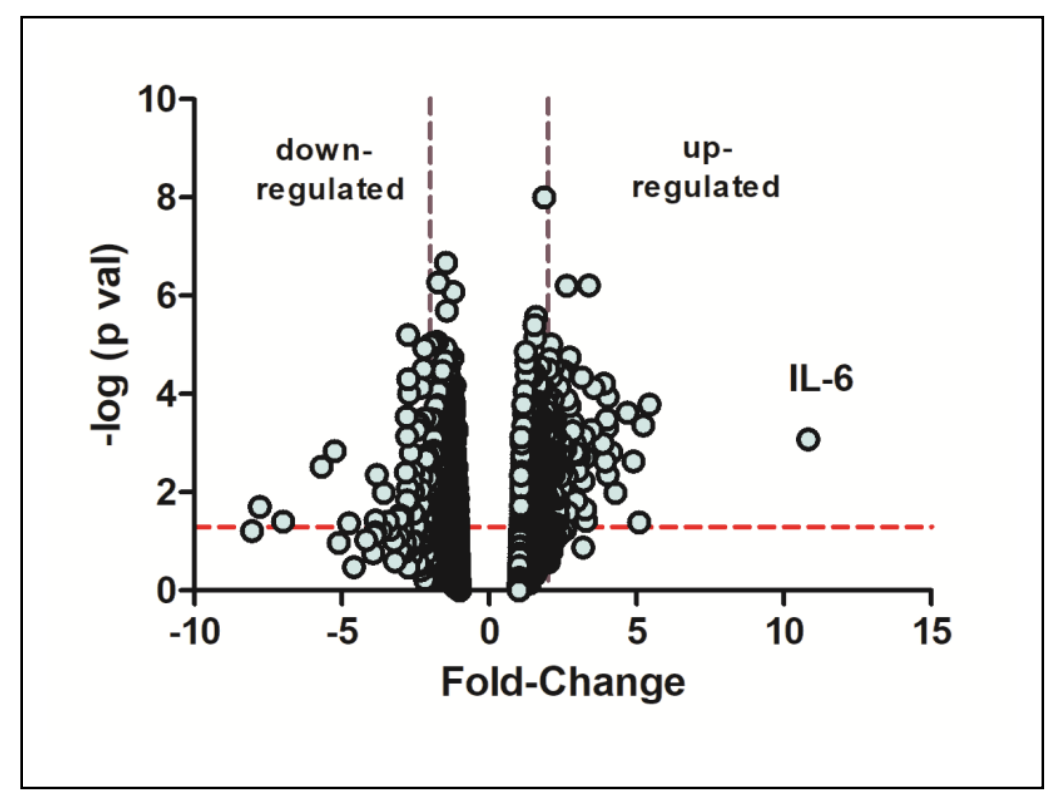

Figure 2. Microarray identifies IL-6 as a gene highly overexpressed in early recovery. A volcano plot of Affymetrix chicken microarray data indicated that 207 genes were found to be significantly differentially expressed by $\geq 2$ fold in recovering choroids as compared with choroids from normal untreated chicks $(p \leq 0.05)$. The horizontal dashed red line indicates where $p=0.05$, with points above the line having $p<0.05$ and points below the line having $p>0.05$. The area between the dashed purple lines indicates points having a fold-change less than |2|. IL-6 was increased by 10.83 fold in recovering choroids compared with normal choroids ( $n=5$ birds in each group) $p=0.00084$, Student's t-test). 
104 IL-6 mRNA was significantly increased in choroids following 45 minutes to 24 hrs of recovery

105 compared to contralateral control eyes (个99 - 1738\%), reaching a maximum following 6 hrs of

106 recovery. By 4 days of recovery, IL-6 mRNA was significantly downregulated in treated choroids,

107 compared with that of treated choroids at 24 hrs of recovery, and was similar to that of fellow

108 control eyes ( $p=0.84$ and 0.12 , for 4 and 8 days of recovery, respectively, paired t-test).

110 hrs following removal of the occluder, prompted us to determine whether increased choroidal

111 IL-6 gene expression was an artifact of removal of the occluder, rather than due to a visual

112 stimulus. To address this possibility, one group of chicks was kept in complete darkness for 6 hrs

113 following removal of the occluder (Figure 3A, "6 hrs in dark"). Interestingly, IL-6 gene expression

114 was significantly lower in both control and recovering eyes, as compared with IL-6 mRNA levels

115 from all other choroids of control, recovering or form deprived eyes reared under normal room

116 light $[p<0.01$, t-test, for choroids of dark reared control or recovering eyes compared with the

117 lowest control group (1.5 hr control group)].

119 recovery, compared to contralateral control eyes ( $\uparrow 36 \%, p<0.01$, paired t-test), but returned

120 to control levels by $24 \mathrm{hrs}$ of recovery (Figure 3B). We also evaluated gene expression of the

121 chicken cytokines, interferon gamma (IFN- $\gamma$ ), interleukin $1 \beta$ (IL-1 $\beta$ ), and TNF- $\alpha$ (TNF- $\alpha)$ in

122 choroids of eyes following 1.5 - 6 hrs of recovery and in contralateral control eyes. Gene

123 expression of TNF- $\alpha$ was substantially higher ( $\approx 7$ fold) than all other cytokines examined, but

124 not significantly different between control and recovering eyes. Only gene expression of IL- 

controls ( $\uparrow 179 \%, p<0.05$, paired t-test) (Figure $3 \mathrm{C}$ ).

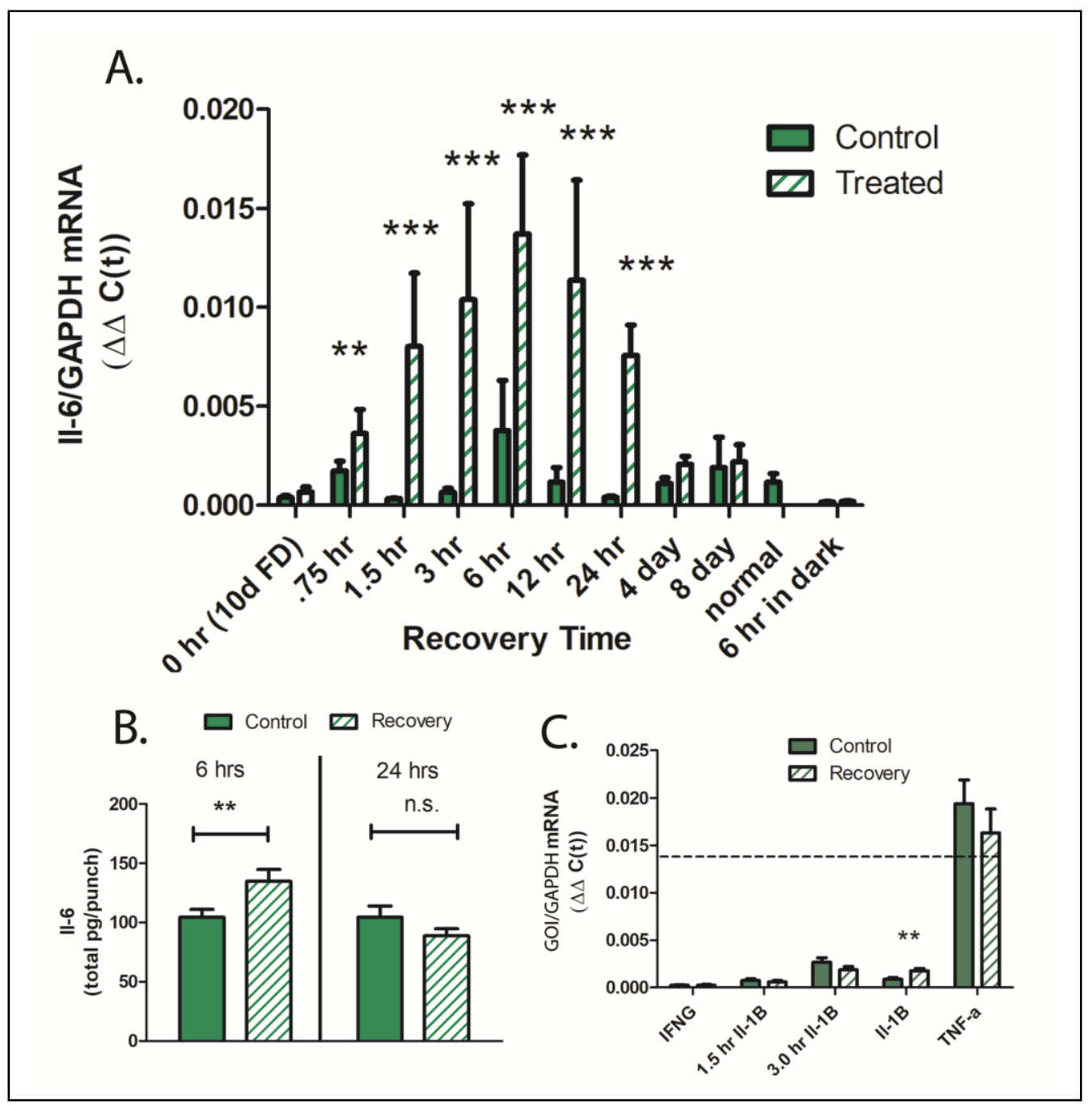

Figure 3. Cytokine gene and protein expression in chick choroids. (A) IL-6 mRNA expression in choroids from control and treated eyes, following 10 days of form deprivation $(0 \mathrm{hr} / 10 \mathrm{~d}$ FD), $0.75 \mathrm{hr}-8$ days of recovery from form deprivation, normal, untreated eyes (normal), and in eyes recovered for $6 \mathrm{hrs}$, but kept in total darkness ( $6 \mathrm{hr}$ in dark) ( $n=5-16$ birds in each group) $* * * p<0.001, * * p<0.01$, paired t-test. (B) IL-6 protein production by control and recovering choroids following 6 and 24 hrs of recovery from induced myopia. Data are expressed as mean \pm SEM $(n=16) * * p<0.01$, paired t-test. (C) Quantification of other proinflammatory cytokines in chick choroids. Gene expression of Interferon gamma (IFNG), interleukin 1B (IL-1B), and tumor necrosis factor alpha (TNF-a) was quantified in control and treated chick choroids following 6 hrs of recovery. Additionally, IL-1B mRNA was quantified following 1.5 and $3 \mathrm{hr}$ of recovery. The dashed line indicates the average IL- 6 expression in $6 \mathrm{hr}$ recovering choroids. ( $\mathrm{n}=6-11$ birds in each group) $* * p<0.01$, paired t-test. 
Light Intensity. Based on our observation that IL-6 mRNA was significantly lower in choroids of

137 birds kept in darkness for $6 \mathrm{hrs}$, compared to control or treated eyes reared under standard room

138 lighting, we evaluated the effect of varied light intensity on choroidal IL-6 gene expression.

139 Normal untreated chicks were kept in dim light (5 lux), medium intensity light (700 lux) and high

140 intensity light (3150 lux), as well as red LED light (58 lux) and blue LED light (111 lux) for 6 hours

141 prior to RNA isolation. Exposure to all light intensities resulted in a significant increase in IL-6

142 mRNA, compared to IL-6 gene expression in choroids of dark reared chicks (Figure 4); however,

143 no differences were observed in IL-6 mRNA levels between the five lighting conditions, with all

144 IL-6 mRNA values similar to that of the normal untreated chick choroids (Figure 3A).

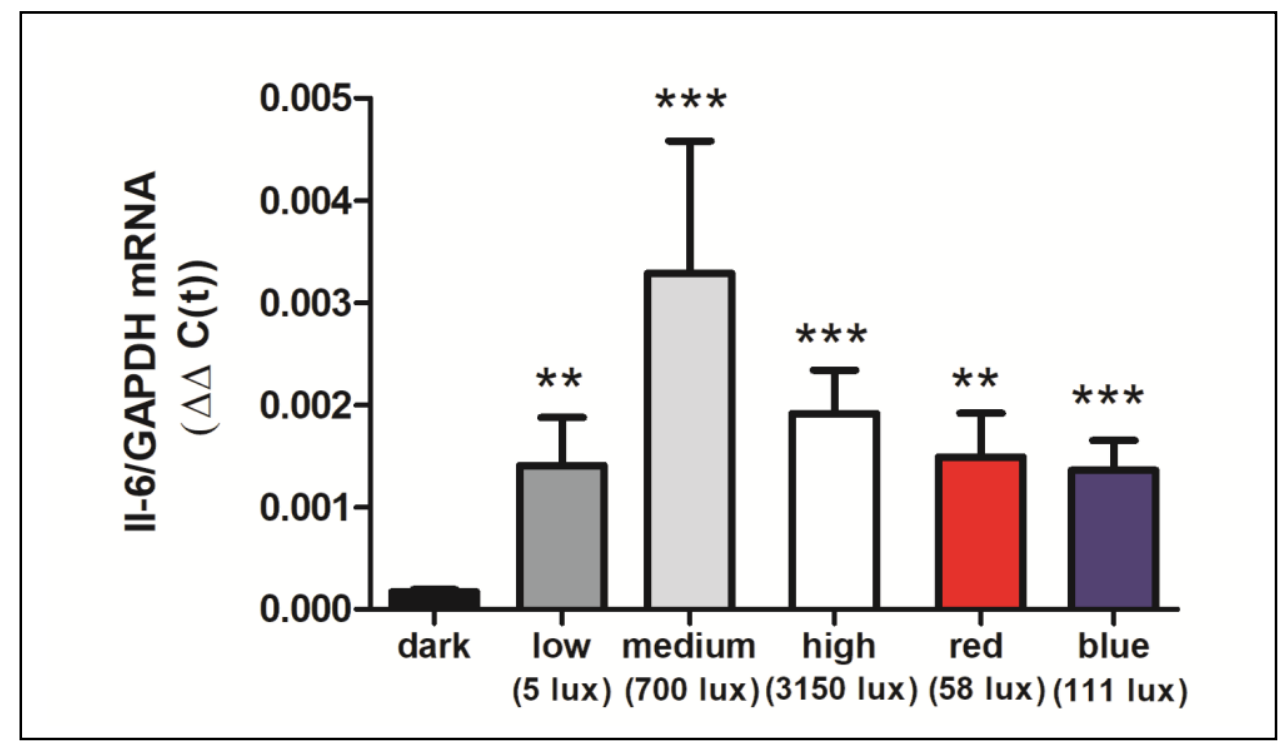

Figure 4. Effect of light intensity on IL-6 mRNA expression. Normal chicks were housed in complete darkness ("dark"), white LED light of varying intensities ("low", 5 lux; "medium", 700 lux; "high", 3150 lux), red LED light ("red", 58 lux), or blue LED light ("blue", 111 lux) for 6 hrs at which time choroids were isolated with II-6 mRNA was quantified by Taqman ${ }^{\text {TM }}$ real time PCR. [ $n=6-8$ birds ( $12-16$ choroids)] in each group. $* * * p<$ $0.001, * * p<0.01$, Kruskal-Wallis test with Dunn's multiple comparisons. 
153 Optical Defocus. Following removal of the occluder, previously form deprived eyes experience

154 myopic defocus due to form deprivation-induced myopia. We therefore determined whether

155 choroidal IL-6 gene expression was affected following a period of imposed myopic or hyperopic

156 defocus via the application of $+15 D$ or $-15 D$ spectacle lenses (Figures 5A \& 5B). Following 24 hrs

157 of +15 D lens wear, choroidal IL-6 gene expression was significantly increased compared with

158 contralateral control eyes ( $\uparrow 48.3 \%, p<0.05$, paired t-test) (Figure $5 \mathbf{C}$ ). No significant differences

159 were detected in IL-6 gene expression following 6 hrs of +15D lens wear. Treatment with -15D

160 lenses had no statistically significant effect on choroidal IL-6 gene expression, although a trend

161 toward decreased expression was noted. Scleral proteoglycan synthesis was also assessed

162 following $24 \mathrm{hrs}$ of lens treatment to confirm that the +15D and -15D lenses were inducing

163 compensatory ocular growth responses (Figure 5D). As expected, treatment with +15D lenses

164 resulted in a significant decrease in scleral proteoglycan synthesis $(P<0.001$, paired $t$-test) and

165 treatment with -15D lenses resulted in a significant increase in scleral proteoglycan synthesis

$166(\mathrm{P}<0.05$, paired t-test). 
A.

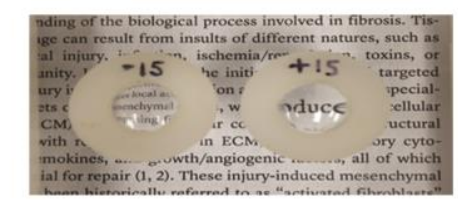

B.
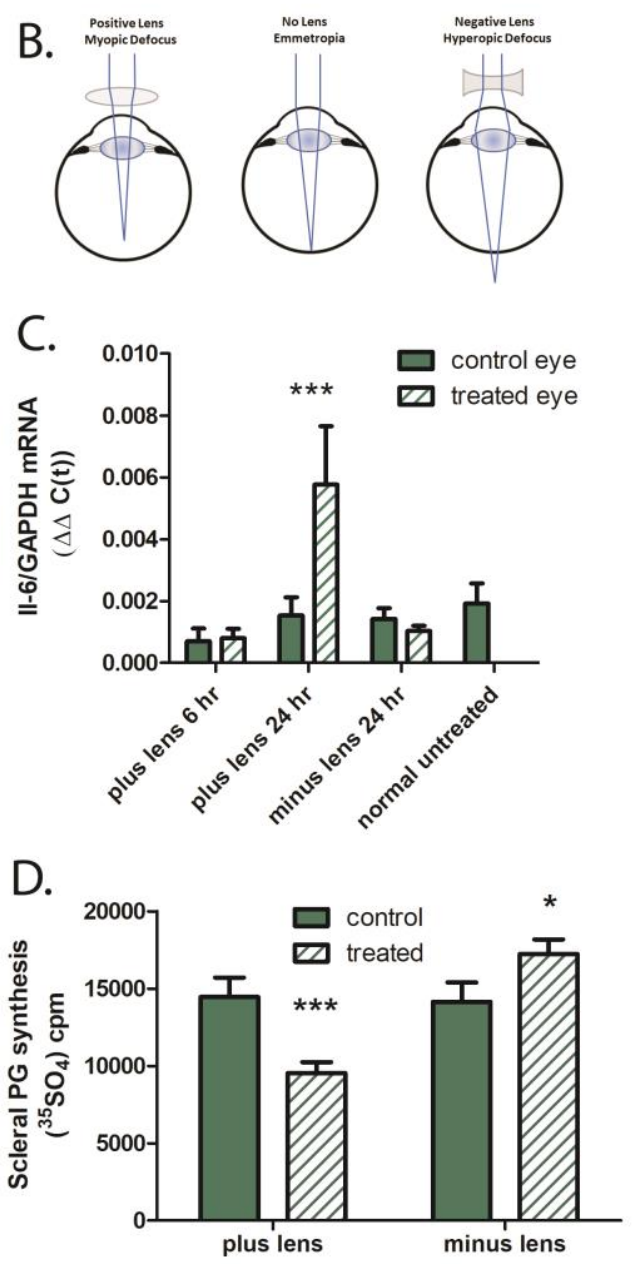

Figure 5. Effect of imposed defocus on choroidal IL-6 gene expression. (A). Spectacle lenses [minus 15D $(-15)$ or plus 15D (+15)] were applied to the right eyes of chicks for $6-24$ hrs. (B). Schematic diagram illustrating the effects of imposed optical defocus on the location of ocular images of distant objects for an emmetropic eye (center); positive lenses move the image plane in front the retina, imposing myopic defocus (left), while negative lenses move the image plane behind the retina, imposing hyperopic defocus (right). (C) IL-6 mRNA expression in choroids from control and treated eyes, following 6 or $24 \mathrm{hr}$ of plus lens wear ( $n=6$ and $n=27$, respectively), $24 \mathrm{hr}$ of minus lens wear $(n=34)$, and normal untreated choroids. $(n=8) . * * * p<0.001$, paired t-test. (D) Scleral proteoglycan synthesis following 24 hrs of lens wear. Proteoglycan synthesis was significantly reduced following $24 \mathrm{hrs}$ of $+15 \mathrm{D}$ lens wear, compared to untreated contralateral control eyes $(* * * p<0.001$, paired t-test, $n=10)$ and was significantly increased following $24 \mathrm{hrs}$ of $-15 \mathrm{D}$ lens wear, compared with untreated contralateral control eyes $(* p<0.05$, paired t-test, $n=13$ ). 


\section{Choroidal IL-6 Synthesis Is Transcriptionally Regulated by NO}

187 Nickla et al., (Nickla, Damyanova et al., 2009) have previously demonstrated that nitric oxide synthesis via neuronal nitric oxide synthase (nNOS) is obligatory for recovery from form deprivation myopia. Administration of the non-specific inhibitor nitric oxide synthase inhibitor, $\mathrm{N}^{\mathrm{a}}$-nitro-L-arginine methyl ester (L-NAME), or the $\mathrm{nNOS}$ inhibitor $\mathrm{N}^{\mathrm{w}}$-propyl-L-arginine, blocks recovery due to inhibition of choroidal thickening and dis-inhibition of scleral proteoglycan synthesis. We therefore investigated the role of nitric oxide on choroidal IL-6 transcription using several approaches. First, L-NAME, or vehicle, was administered via intravitreal injection to chick eyes following 10 days of form deprivation. Chicks were then given unrestricted vision for 6 hours and choroidal IL-6 mRNA was quantified (Figure 6A). Following 6 hrs of recovery, IL-6 mRNA was significantly increased in recovering eyes of vehicle (saline) treated eyes compared with contralateral control eyes ( $1107 \%, \mathrm{p}<0.0001$, paired t-test). Administration of L-NAME just prior to recovery resulted in a significant decrease in choroidal IL-6 mRNA, 6 hrs following LNAME administration, as compared with choroidal IL-6 mRNA levels in recovering eyes of salinetreated eyes ( $p<0.05$, Mann Whitney U test). L-NAME administration did not completely abolish

201 the recovery-induced rise in choroidal IL-6 mRNA; IL-6 mRNA levels in choroids of L-NAME202 treated eyes were significantly higher than that of contralateral untreated eyes $(p<0.01$, paired 203 t-test). As previously reported (Summers Rada \& Hollaway, 2011), scleral proteoglycan synthesis 204 was significantly increased in the posterior sclera of chick eyes during the development of form 205 deprivation myopia (Day 0 of recovery) $(\mathrm{p}<0.001$, paired t-test) and was rapidly downregulated 206 following 12 hrs of recovery to levels similar to that of contralateral control eyes (vehicle) (Figure 
6B). Intravitreal application of L-NAME inhibited this recovery response, resulting in a significant

210 ( $p<0.05$, Mann-Whitney U test). These results confirm that intravitreal administration of L-NAME

211 in our study resulted in the same effects on eye growth as have been previously reported.

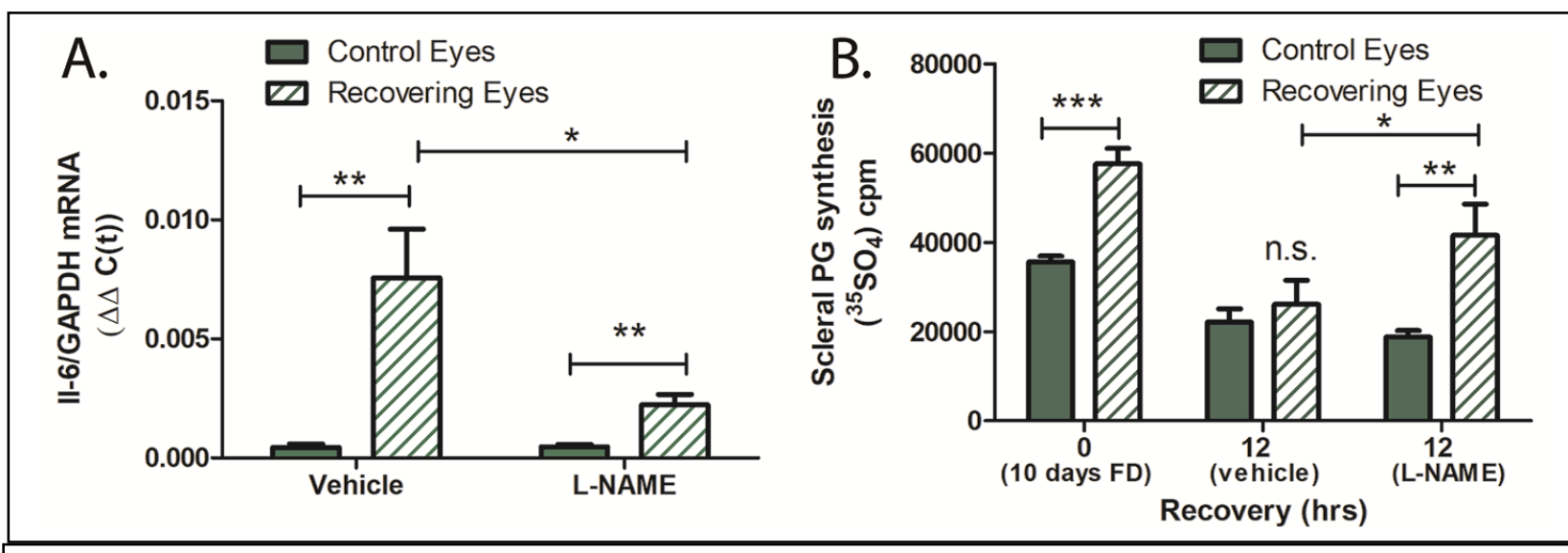

Figure 6. L-NAME inhibits choroidal IL-6 transcription and recovery. (A) Intravitreal injection of L-NAME (16.2 $\mu$ mole/eye) immediately prior to recovery significantly reduced IL-6 mRNA levels compared to recovering eyes receiving vehicle only $(0.9 \% \mathrm{NaCl})\left({ }^{*} p<0.05\right.$, MannWhitney $\mathrm{U}$ test, $\mathrm{n}=7 ;{ }^{*} \mathrm{p}<0.01$, paired t-test, $\mathrm{n}=7$ ). (B) L-NAME disinhibits scleral proteoglycan synthesis in recovering eyes. Following $12 \mathrm{hrs}$ of recovery from 10 days of form deprivation (FD), scleral proteoglycan synthesis decreased to control levels in vehicle-treated eyes, but remains significantly increased over control levels in L-NAME treated eyes. ( ${ }^{* * *} \mathrm{p}<$ $0.001,{ }^{*} p<0.01$ paired t-test, $n=16$ and $17 ;{ }^{*} p<0.05$, Mann-Whitney $U$ test, $\left.n=17\right)$.

214 transcription, suggesting that NO is involved in the regulation of choroidal IL-6 mRNA

215 transcription. Therefore, as a second approach to evaluate NO on choroidal IL-6 transcription, we

216 tested the effect an NO donor on IL-6 gene transcription in isolated chicken choroids (Figure 7).

217 Treatment of choroids with PAPA-NONOate, an NO donor with a half-life of 15 min at $37^{\circ} \mathrm{C}$, led

218 to a concentration dependent increase in IL-6 mRNA that reached a 5-fold increase at $1.5 \mathrm{mM}$ 
219 (Figure 7A). Protein expression of IL-6 was also significantly increased in isolated choroids

220 following incubation with PAPA-NONOate, compared to that of choroids incubated in culture

221 medium alone ( $\uparrow 30.52 \%$, and $\uparrow 131.77 \%$ for control vs 3 mM PAPA-NONOate and control vs 5

222 mM PAPA-NONOate; $p<0.05, p<0.0 .01$, respectively, ANOVA with Bonferonni's correction),

223 (Figure 7B).

224

As NO has been shown to activate members of the MAPK pathway in a cGMP-

225 independent manner, and given that the p38 pathway plays essential roles in the production of

226 IL-6 and other proinflammatory cytokines (IL-1 $\beta$, TNF- $\alpha$ and IL-6) (Guan, Buckman et al., 1998),

227 we sought to determine whether p38 MAPK activation contributes to the NO mediated

228 stimulation of choroidal IL-6 transcription. Treatment of isolated choroids with the p38 specific

229 inhibitor, SB203580, and PAPA-NONOate abolished the NO-induced increase in IL-6 mRNA,

230 suggesting that the NO-stimulated IL-6 transcription is mediated through activation of MAPK

231 signaling pathways (Figure 7C).

232

233

234

235

236

237

238

239

240 


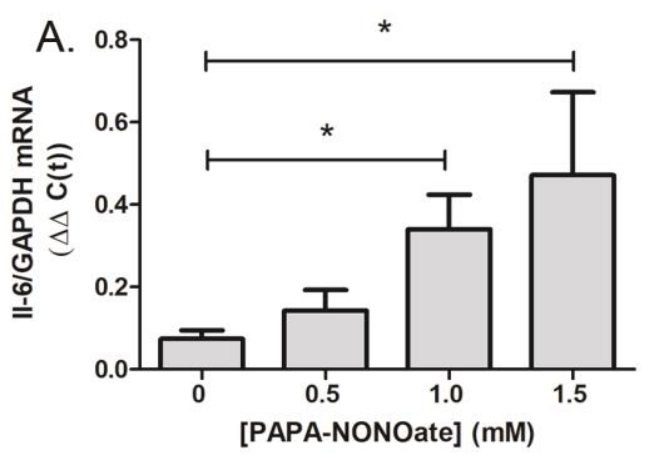

B.
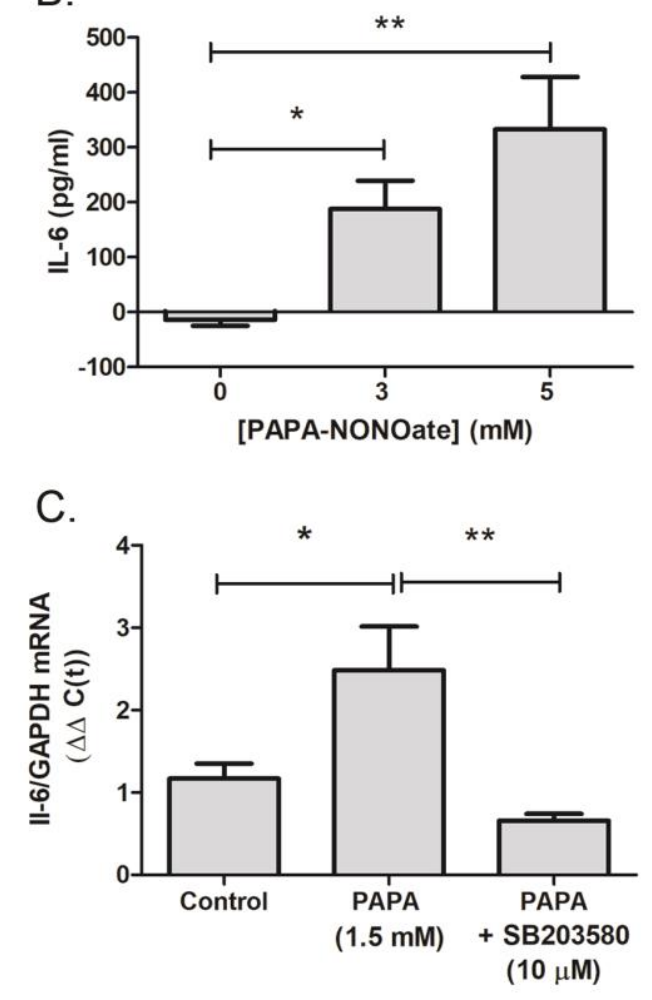

Figure 7. The NO donor, PAPA-NONOate, stimulates choroidal IL-6 production. Choroids were isolated from normal chicken eyes and were incubated with the indicated concentrations of PAPA-NONOate for $24 \mathrm{hrs}$. (A) IL-6 gene expression was significantly increased in choroids following incubation in 1.0 and $1.5 \mathrm{mM}$ PAPA-NONOate $\left({ }^{*} p<0.05\right.$, ANOVA with Bonferonni's correction, $n=4-5$ choroids in each group). (B) IL-6 protein concentrations were significantly increased in choroid culture supernatants following incubation with $3-5$ mM PAPA-NONOate $\left(* * p<0.01,{ }^{*} p<0.05\right.$, ANOVA with Bonferonni's correction, $n=3$ - 5 choroids in each group). (C) Incubation of chicken choroids with PAPANONOate (1.5 mM) together with the p38 MAPK inhibitor SB203580 (10 $\mu \mathrm{M})$ abolished the PAPA-NONOate-induced increase in IL-6 mRNA $\left({ }^{* *} p<0.01,{ }^{*} \mathrm{p}<0.05\right.$, Student's t-test, $\mathrm{n}=$ 10 choroids in each group). 

clinical trials (Upadhyay \& Beuerman, 2020) and in avian and mammalian animal models of myopia, although the mechanism of action is poorly understood (McBrien, Moghaddam et al., 1993, Whatham, Lunn et al., 2019). Therefore, we examined the effect of atropine on choroidal

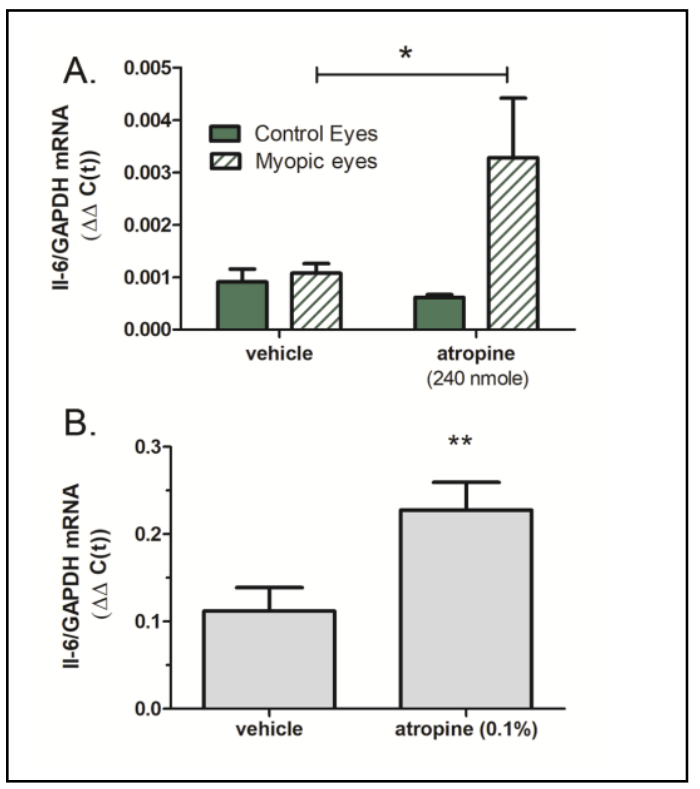

Figure 8. Atropine stimulates choroidal IL-6 gene expression. (A) Intravitreal injection of atropine (240 nmole/eye) into chick eyes following 14 days for form deprivation (Myopic eyes) increased IL-6 mRNA levels compared to myopic eyes receiving vehicle only (PBS) ( ${ }^{*} p<0.05$, Mann-Whitney $U$ test, $n=18$ ). (B) Incubation of chicken choroids in organ culture with $0.1 \%$ atropine for $24 \mathrm{hrs}$ significantly increased choroidal IL- 6 gene expression. ( ${ }^{* *} p<0.01$, Student's t-test, $n=16$ ). 


\section{Discussion}

expressed in and released by the choroid during the recovery from form deprivation myopia.

279 Choroidal upregulation of IL-6 is rapid; significant increases in gene expression were observed

280 after only 45 minutes of unrestricted vision. The visual stimulus for choroidal IL- 6 gene expression

281 is myopic defocus, as a similar rise in IL-6 is observed after 6 hrs of positive (+15D) lens wear.

282 Finally, nitric oxide appears to directly or indirectly upregulate choroidal IL-6 gene expression.

We and others have previously shown that changes in the visual environment can cause

synthesis, choroidal retinoic acid synthesis, and choroidal thickness [reviewed in (Troilo et al.,

291 we demonstrate that myopic defocus, as a result of prior form vision deprivation, or due to

292 application of +15 D lenses, stimulates choroidal IL-6 gene expression. In contrast, induction of

293 hyperopic defocus through the application of $-15 D$ lenses resulted in a slight decrease in

294 choroidal IL-6 gene expression, that did not reach statistical significance in the present

295 study. Choroidal IL-6 gene expression was not significantly affected by rearing chicks in varying

296 light intensities (5 - 3150 lux), or rearing in constant red or blue LED light (58 and 111 lux,

297 respectively), but was significantly lower in choroids from chicks reared in constant darkness for 
$6 \mathrm{hrs}$, compared with birds reared in any other light conditions examined. Protein levels of IL- 6 were also significantly increased in choroids of recovering eyes following 6 hrs of recovery, but were not significantly different following $24 \mathrm{hrs}$ of recovery. We suspect that IL-6 protein is released from choroids and either enters the circulation or adjacent ocular tissues shortly after its synthesis as has been described for IL-6 in skeletal muscle (Steensberg, van Hall et al., 2000). recovery/myopic defocus does not appear to be due to a general inflammatory response, as other pro-inflammatory cytokines, IFN- $\gamma$ and TNF- $\alpha$ were unaffected by visual manipulations. ILof recovery, suggesting that changes in IL-1B gene expression are downstream to that of IL-6.

312 in choroidal thickness, as well as the duration of the response to lens wear (Zhu, Park et al., 2005).

313 If IL-6 is involved in mediating changes in choroidal thickness, we would predict that myopic

314 defocus-induced increases in choroidal IL-6 gene and protein expression would induce changes

315 in choroidal thickness that would outweigh and outlast the minor reduction in IL-6 expression

316 induced by brief periods of hyperopic defocus.

317 If choroidal IL-6 gene expression is causally related to ocular changes associated with

318 recovery from myopia, then agents known to block recovery should also block choroidal IL-6 
320 following intravitreal application of the nitric oxide synthase inhibitor, L-NAME. L-NAME has

321 previously been shown to prevent choroidal thickening and disinhibit scleral proteoglycan

322 synthesis during recovery from induced myopia and in response to positive lens wear (Nickla,

323 Wilken et al., 2006). We found that intravitreal treatment with L-NAME significantly attenuated

324 the recovery-induced increase in choroidal IL-6 gene expression, indicating that nitric oxide either

325 directly or indirectly regulates choroidal IL-6 gene expression. Treatment of isolated choroids

326 with the NO donor, PAPA-NONOate stimulated IL-6 gene and protein expression, confirming that

327 choroidal IL-6 is upregulated by NO. NO has been reported to stimulate IL-6 production in skeletal

328 myocytes (Makris, Sotzios et al., 2010), human blood mononuclear cells (Siednienko, Nowak et

329 al., 2011) and kidney epithelial cells (Demirel, Vumma et al., 2012) by activating ERK1/2 and p38

330 MAPK-signaling pathways. We also found that p38 MAPK signaling was crucial for the PAPA-

331 NONOate-mediated activation of IL-6 in chick choroids as incubation with the p38 MAPK

332 inhibitor, SB203580, abolished PAPA-NONOate-stimulation of IL-6 gene expression.

In the present study, since L-NAME was delivered intravitreally and NO was applied

334 directly to the choroid, it is unclear as to cellular source of NO generated in response to myopic

335 defocus that is responsible for IL-6 upregulation. NO and nNOS (NOS1) have been detected in

336 virtually all retinal neurons, in the RPE, and in several cell types in the chick choroid (Fischer \&

337 Stell, 1999, WD, 2000). It is unlikely that choroidally-derived NO is responsible for IL-6

338 upregulation in the choroid, as application of the NO substrate, L-arginine (which is catalyzed to

339 L-citrulline and NO by the NOS enzymes) had no significant effect on choroidal IL-6 synthesis

340 (Supplementary Figure S1). We speculate that NO, released from the retina or RPE diffuses to

341 the choroid to stimulate IL-6 synthesis. It is also unclear as to the cellular source of choroidal IL- 
3426 in response to myopic defocus. Our immunohistochemical evaluation of IL-6 protein

343 distribution indicated that IL-6 was present as discrete puncta in the RPE, choroidal vascular

344 endothelial cells and extravascular stromal cells. Any of these cells, as well as myeloid and

345 Iymphoid cells, could be the source of visually induced IL-6. However, IL-6-positive choroidal cells

346 identified in the present study may indicate internalization of IL-6 following synthesis and

347 secretion by neighboring cells via a paracrine signaling mechanism.

$348 \quad$ Atropine has been shown to prevent experimentally-induced myopia in chicks and inhibits

349 myopia development in some children when applied topically (Chia, Chua et al., 2012). We

350 therefore evaluated choroidal IL-6 gene expression following in vivo and in vitro treatment with

351 atropine. We found that a single intravitreal injection of atropine to chicks undergoing form

352 deprivation-induced myopia stimulated choroidal IL-6 gene expression. Moreover, incubation of

353 isolated choroids with $0.1 \%$ atropine also stimulated choroidal IL-6 gene expression, suggesting

354 that atropine acts directly on the choroid to stimulate IL-6 gene expression.

355 Conclusions

In the present study, we report that myopic defocus, either in eyes recovering from

357 induced myopia, or in eyes treated with +15D spectacle lenses, stimulates IL-6 mRNA and protein

358 synthesis in the chick choroid. The ramifications of increased choroidal IL-6 synthesis are unclear.

359 In the context of ocular growth control, it appears that choroidal IL-6 is associated with a slowing

360 of eye growth, as it is upregulated in recovering eyes (when eyes are decelerating their rate of

361 elongation) and in myopic eyes treated with atropine, an agent known to inhibit vitreous

362 chamber elongation and myopia. Moreover, IL-6 mRNA is downregulated in recovering eyes

363 treated with L-NAME, a compound known to inhibit recovery and increase scleral proteoglycan 
364 synthesis and ocular elongation. Treatment of isolated sclera with IL-6 had no effect on scleral

365 proteoglycan synthesis (Supplementary Figure S2), indicating that additional downstream

366 mediators, most likely derived from the choroid, are responsible for regulating the scleral

367 changes associated with recovery.

368 On the other hand, studies have shown that IL-6 has a major role in the pathology of

369 uveitis, glaucoma, retinal vein occlusion, macula edema and diabetic retinopathy (Zahir-Jouzdani,

370 Atyabi et al., 2017). IL-6 induces ocular inflammatory responses often leading to the breakdown

371 of the blood ocular barrier, angiogenesis, increased vascular permeability and choroidal

372 neovascularization. Based on the results of the present study, it is possible that myopic defocus

373 in humans, as a result of uncorrected myopia, may cause elevated choroidal IL-6 which could

374 predispose individuals to one or more of the above serious ocular complications.

375 The identification of small molecule or biological approaches to manipulate choroidal IL-

3766 concentrations will elucidate the role of choroidal IL-6 in postnatal ocular growth, as well as in

377 a variety of ocular conditions. 


\section{Materials and methods}

387 Ethics and Animals. Animals were managed in accordance with the ARVO Statement for the Use of Animals in Ophthalmic and Vision Research, with the Animal Welfare Act, and with the National Institutes of Health Guidelines. All procedures were approved by the Institutional Animal Care and Use Committee of the University of Oklahoma Health Sciences Center. White Leghorn male chicks (Gallus gallus) were obtained as 2-day-old hatchlings from Ideal Breeding Poultry Farms (Cameron, TX). Chicks were housed in temperature-controlled brooders with a 12hour light/dark cycle and were given food and water ad libitum. At the end of experiments, chicks were euthanized by overdose of isoflurane inhalant anesthetic (IsoThesia; Vetus Animal Health, Rockville Center, NY), followed by decapitation.

Visual Manipulations. Form deprivation myopia (FDM) was induced in 3 to 4 day-old chicks by

397 applying translucent plastic goggles to one eye, as previously described (Rada, Thoft et al., 1991).

398 The contralateral eyes (left eyes) of all chicks remained untreated and served as controls. Chicks were checked daily for the condition of the goggles. Goggles remained in place for 10 days, after

400 which time the goggles were removed and chicks were allowed to experience unrestricted vision

401 (recover) for up to 4 days. When multiple time points were assessed in one experiment, chicks 402 were randomly assigned to groups for each time point.

404 lenses to 3 to 4 day old chicks. Lenses were fashioned from PMMA hard contact lenses [12 mm 405 diameter, $8 \mathrm{~mm}$ base curve, Conforma Labs, Inc (Norfolk, VA)] that were mounted onto nylon 
407 was glued to the back of the nylon washer for mounting around the chick's right eye using cyanoacrylate adhesive. Lenses remained in place for up to $24 \mathrm{hrs}$. with Multicolor (RGB) and White LED strip lights at the top surface of the cage and light intensity

411 was controlled using a wireless RF remote (Super Bright LEDs, Inc., St. Louis, MO). Light intensity

412 (5 lux - 3150 lux) was measured using a light meter (Datalogger Model 401036, Extech

413 Instruments, Nashua, $\mathrm{NH}$ ) at a distance of $8 \mathrm{~cm}$ from the bottom of the cage (approximate eye-

414 level of chicks). Chicks were randomly assigned to white, red or blue light and housed in LED 415 cages for $6 \mathrm{hrs}(9: 30 \mathrm{am}-3: 30 \mathrm{pm})$. A separate group of chicks was kept in complete darkness for $4166 \mathrm{hrs}$.

417 Intravitreal injections. Injections were delivered using a NanoFil-100 syringe with a 26G needle 418 (World Precision Instruments, Sarasota, $\mathrm{FL})$ under isofluorane $\left(0.8 \%\right.$ in $\mathrm{O}_{2}$; IsoThesia; Vetus 419 Animal Health, Rockville Center, NY) inhalation anesthesia at a flow rate of 0.4 liters/minute using 420 an Isoflurane Anesthesia machine for veterinary use only (Ohmeda Anesthesia Service and 421 Equipment, Inc., Atlanta, GA). Following removal of the occluder, the sclera was exposed by 422 retracting the eyelids with a handmade ocular speculum and injections were delivered through

423 the sclera at the superior margin of the globe, just outside of the scleral ossicles, after cleaning 424 the eye lids and surround area with 70\% alcohol. Injections consisted of L-NAME (Sigma Chemical 425 Co., St. Louis, MO) (a $30 \mu$ linjection containing $16.2 \mu$ mole of L-NAME in $0.9 \%$ saline), $30 \mu$ l of 426 0.9\% saline (vehicle for L-NAME) (Nickla \& Wildsoet, 2004), atropine sulfate (Sigma Chemical Co.)

427 (a $20 \mu \mathrm{l}$ injection containing 240 nmoles of atropine sulfate in phosphate buffered saline, PBS), 428 and $20 \mu \mathrm{l}$ of PBS (vehicle for atropine sulfate)(Carr \& Stell, 2016). The needle remained in place 
429 for 15 seconds before slowly withdrawing it from the eye and an ophthalmic antibiotic ointment

430 (Vetropolycin, Pharmaderm, Melvill, New York) was applied to the eye. In some cases, the

431 occluders were replaced prior to prior to awakening from the anesthesia.

432 Tissue Preparation. Chicks were euthanized by an overdose of isoflurane inhalant anesthetic

433 (IsoThesia; Vetus Animal Health) following 10 days of form deprivation (day 0 recovery), after

434 various time points of recovery, following lens wear, or light exposure. Eyes were enucleated and

435 cut along the equator to separate the anterior segment and posterior eye cup. Anterior tissues

436 were discarded, and the vitreous body was removed from the posterior eye cups. An 8 mm punch

437 was taken from the posterior pole of the chick eye using a dermal biopsy punch (Miltex Inc., York,

438 PA). Punches were located nasal to the exit of the optic nerve, with care to exclude the optic

439 nerve and pecten oculi. With the aid of a dissecting microscope, the retina and majority of RPE

440 were removed from the underlying choroid and sclera with a drop of phosphate buffered saline

441 (PBS; $3 \mathrm{mM}$ dibasic sodium phosphate, $1.5 \mathrm{mM}$ monobasic sodium phosphate, $150 \mathrm{mM} \mathrm{NaCl}, \mathrm{pH}$

442 7.2) and gentle brushing. For microarray, Taqman real time PCR, and ELISA assays, choroids were

443 separated from the sclera using a small spatula, placed in $2 \mathrm{ml}$ screw cap tubes, and snap frozen

444 in liquid nitrogen and stored at $-80^{\circ} \mathrm{C}$. For immunolabelling experiments, choroids with sclera still

445 attached were placed into a 48-well flat bottom plate (Corning Inc., Corning, NY). A small amount

446 of RPE was left on the choroids to discriminate between the RPE and scleral side of the tissue.

447 The tissues were then fixed with $4 \%$ paraformaldehyde (stock solution freshly prepared) in PBS

$448 \mathrm{O} / \mathrm{N}$ at $4^{\circ} \mathrm{C}$.

449 Immunolabelling of Chick Choroids. Punches $(5 \mathrm{~mm})$ containing retina, RPE choroid, and sclera

450 were obtained from the posterior poles of control and recovering chick eyes, fixed in neutral- 
451 buffered formalin, and embedded in paraffin, and sections were obtained. Tissue sections of

452 posterior ocular tissues were deparaffinized through a graded series of xylenes and ethanol and

453 rinsed in PBS, and then incubated for $30 \mathrm{~min}$ at RT in incubation buffer that consisted of $2 \%$ BSA

454 (Sigma Chemical Co.) and $0.2 \%$ Triton X-100 in PBS. Sections were incubated overnight at $4{ }^{\circ} \mathrm{C}$

455 with rabbit anti-chick IL-6 (Bio-Rad Laboratories, Inc., Hercules, CA) diluted 1:20 in incubation

456 buffer. For negative controls, tissue sections were incubated in $25 \mu \mathrm{g} / \mathrm{ml}$ nonimmune rabbit

457 immunoglobulin (Sigma Chemical Co.) instead of the IL-6 antibody. Additional pre-absorption

458 controls were performed in which the anti-IL-6 antibody was incubated overnight at $4{ }^{\circ} \mathrm{C}$ with a

45910 fold molar excess of recombinant chicken IL-6 (1.67 $\mu \mathrm{M}$; Bio-Rad Laboratories, Inc.) before

460 immunolabeling fixed sections of chick ocular tissues. Following overnight incubation with the

461 primary antibody, sections were rinsed in PBS, and incubated for $30 \mathrm{~min}$ at RT in $5 \mu \mathrm{g} / \mathrm{ml}$ of goat

462 anti-rabbit AlexaFluor 488 (ThermoFisher Scientific, Richardson, TX). Sections were rinsed in PBS

463 and then incubated for $10 \mathrm{~s}$ at RT with $0.0005 \%$ DAPI nuclear stain, followed by a final rinse in

464 PBS. Coverslips were mounted onto the slides with Prolong Gold Antifade reagent containing

465 DAPI (ThermoFisher Scientific), and the immunolabeled sections were examined under an

466 Olympus Fluoview 1000 laser-scanning confocal microscope (Center Valley, PA).

467 Microarray Analyses. Choroids were isolated from 10 normal chick eyes ( $n=5$ chicks) and from

468 control and treated chicks eyes following 6 hrs of recovery from 10 days of prior form

469 deprivation-induced myopia ( $n=5$ chicks) and kept at $-80 \circ \mathrm{C}$ until processed. Choroids were

470 shipped on dry ice to the Microarray Core Facility at the University of Tulsa (Tulsa, Oklahoma).

471 When processing began the samples were moved to a container of liquid nitrogen. The choroids

472 were pulverized using a frozen $1.5 \mathrm{~mL}$ disposable pestle. Immediately following pulverization 
473 the samples were immersed in $300 \mu \mathrm{L}$ of Ambion TriReagent (Applied Biosystems, Foster City,

474 CA) solution and homogenized for 90 seconds with a Pellet Mixer. An additional $700 \mu \mathrm{L}$ of

475 TriReagent was pipetted into the sample after homogenization. Incubation of samples occurred

476 for 5 min using a $1.5 \mathrm{~mL}$ microfuge tube shaker at room temperature. The samples were then

477 transferred to pre-spun Phase Lock Gel Heavy $2 \mathrm{~mL}$ Gel tubes (5 Prime Inc., Gaithersburg, MD).

$478200 \mu \mathrm{L}$ of chloroform was added to each sample, inverted 12 times, and incubated at room

479 temperature for $5 \mathrm{~min}$. The samples were then spun at $20 \mathrm{C}$ for $20 \mathrm{~min}$. $500 \mu \mathrm{L}$ supernatant was

480 poured into $2 \mathrm{~mL}$ round bottom tubes. These tubes were placed into the Qiagen Qiacube robotic

481 workstation and cleaned using the RNeasy Lipid Tissue Mini Kit (Qiagen, Redwood City, CA). The

482 samples were eluted in $50 \mu \mathrm{L}$ of molecular biology water. The samples were also split into two

$48325 \mu \mathrm{L}$ aliquots to ensure sample safety.

484

Following RNA isolation, the samples were quantified using a NanoDrop 1000

485 spectrophotometer (ThermoFisher Scientific). The initial average sample concentration ranged

486 from $20-88 \mathrm{ng} / \mu \mathrm{L}$. The initial RNA 260/280 ratios were between 1.8 and 2.0 with the 260/230

487 ratios between 0.08 and 1.9. Precipitation of one aliquot of RNA was performed to increase the

488 sample concentration and purity. This procedure was performed by addition of 2.5 volumes of

489 ice cold $100 \% \mathrm{EtOH}, 1 / 10$ of $3 \mathrm{M}$ ammonium acetate, and $1 \mu \mathrm{L}$ of glycogen at $5 \mathrm{ng} / \mu \mathrm{L}$. The samples

490 were incubated at -20 C overnight. The samples were spun at 4 ㅇ C for 30 min to pellet the RNA.

491 The supernatant was removed and the pellet was washed with ice cold $80 \%$ EtOH to remove

492 remaining salt. The EtOH was aspirated off and the pellet was dried at room temperature for 5

493 min. Molecular biology water was used to re-suspend the RNA pellet. The amount of water used

494 was calculated to bring the sample concentration to between $58-133 \mathrm{ng} / \mu \mathrm{L}$. After precipitation 
the $260 / 280$ ratios are between 2.0 and 2.1 and the $260 / 230$ ratios are between 1.8 and 2.1. 150 ng of each sample was and processed with the Affymetrix 3' IVT Express Kit (ThermoFisher

497 Scientific).

498 TaqMan Quantitative PCR (RT-Quantitative PCR). Choroids were isolated from individual pairs

499 of control and treated eyes and snap frozen in liquid nitrogen. Total RNA was isolated using

500 TRIzol reagent (ThermoFisher Scientific) followed by DNase treatment (DNA-free, Applied

501 Biosystems) as described previously (Summers, Harper et al., 2016). RNA concentration and

502 purity were determined via the optical density ratio of 260/280 using a Nanodrop ND-1000

503 spectrophotometer and stored at $-80{ }^{\circ} \mathrm{C}$ until use. cDNA was generated from DNase-treated

504 RNA using a High Capacity RNA to cDNA kit. Real time PCR was carried out using a Bio-Rad CFX

505 96. 20- $\mu$ l reactions were set up containing $10 \mu \mathrm{l}$ of TaqMan 2x Universal Master Mix (Applied

506 Biosystems), $1 \mu \mathrm{l}$ 20×6-carboxyfluorescein (FAM)-labeled Assay Mix (Applied Biosystems), and

$5079 \mu$ of cDNA. Each sample was set up in duplicate with specific primers and probed for chicken

508 IL-6 (assay ID number Gg03337980_m1), chicken interferon $\gamma$ (INFG, assay ID number

509 Gg03348618_m1), chicken IL-1 $\beta$ (IL1 $\beta$, assay ID number Gg03347154_g1), chicken TNF- $\alpha$ (LITAF,

510 assay ID number Gg03364359_m1) and the reference gene chicken GAPDH (assay ID number

511 Gg03346982_m1) (Thermofisher Scientific). The PCR cycle parameters were an initial denaturing

512 step at $95{ }^{\circ} \mathrm{C}$ for $10 \mathrm{~min}$ followed by 45 cycles of $95^{\circ} \mathrm{C}$ for $15 \mathrm{~s}$ and $60{ }^{\circ} \mathrm{C}$ for $1 \mathrm{~min}$. Normalized

513 gene expression was determined by the $\Delta \Delta c(t)$ method (Livak \& Schmittgen, 2001) using Bio-Rad

514 CFX Manager ${ }^{\mathrm{TM}}$ version 3.1 and reported values represent the average of duplicate samples.

515 IL-6 protein measurements. Punches $(8 \mathrm{~mm})$ of chick choroids were rinsed in ice-cold PBS (0.01

$516 \mathrm{M}, \mathrm{pH}$ 7.2) and homogenized in $300 \mu \mathrm{l}$ of PBS on ice (Omni Tip, Omni International, Kennesaw, 
517 GA). The resulting suspension was sonicated with an ultrasonic homogenizer (Pulse 150,

518 Benchmark Scientific, Edison, NJ) and subjected to two freeze-thaw cycles to further break the

519 cell membranes. Homogenates were then centrifugated for 5 minutes at $5000 \times$ g. Following

520 centrifugation, pellets were discarded and the supernatants stored at $\leq-20^{\circ} \mathrm{C}$. IL- 6 was measured

521 on duplicate samples using a commercially available chicken IL-6 ELISA kit (Aviva Systems Biology,

522 Corp., San Diego, CA) according to the manufacturer's instructions. Protein concentrations in

523 choroidal lysates were determined on duplicate samples by Bradford assay. Reported values

524 represent the average of duplicate samples.

525 Organ Culture. Choroids were isolated from eyes from adult chicken heads, (Animal

526 Technologies, Inc., Tyler, Texas) as described above and placed in 48-well plates containing 300

$527 \mu \mathrm{l}$ culture medium [1:1 mixture of Dulbecco's Modified Eagle's Medium and Ham's F12 containing

528 streptomycin $(0.1 \mathrm{mg} / \mathrm{ml})$, penicillin $(100 \mathrm{units} / \mathrm{ml})$ and gentamicin $(50 \mathrm{ug} / \mathrm{ml})$ ] in the presence of

529 the NO donor, PAPA-NONOate $(0.5-5 \mathrm{mM}$ in culture medium; Cayman Chemical, Ann Arbor,

$530 \mathrm{MI}$ ), the p38 MAPK inhibitor, SB203580 (10 $\mu \mathrm{M}$; Sigma), atropine sulfate (0.1\%; Sigma) or culture

531 medium alone in a humidified incubator with $5 \% \mathrm{CO}_{2}$, overnight at $37^{\circ} \mathrm{C}$. Following incubation,

532 choroids were snap frozen and RNA isolated for TaqMan real time PCR assays, and medium

533 harvested and frozen for IL-6 ELISA assays.

534 Scleral Sulfated Glycosaminoglycan Synthesis. The posterior hemispheres of eyes of FD chicks (=

5350 days of recovery), or from eyes from chicks recovering from FD myopia for $1-20$ days and

536 contralateral controls were obtained and one $5 \mathrm{~mm}$ tissue punch was excised from the posterior

537 sclera of control and treated eyes using a dermal punch (Miltex Instrument Co.). All retina, RPE,

538 choroid, vitreous, pectin, and muscle were gently cleaned from each sclera punch. Scleral 
539 punches were initially placed into wells of a 96 well culture plate with $50 \mu$ l of N2 medium [Ham's

540 F-12/DMEM containing 1x N2 supplement (Stem Cell Technologies, Vancouver, BC) until all sclera

541 were obtained. Scleral punches were then transferred to $\mathrm{N} 2$ medium containing ${ }^{35} \mathrm{SO}_{4}(100$

$542 \mu \mathrm{Ci} / \mathrm{ml}$; New England Nuclear, MA) and incubated for $3 \mathrm{hr}$. at $37^{\circ} \mathrm{C}$. Radiolabelled scleral punches

543 were digested with proteinase K (protease type XXVIII, Sigma Chemical Co.), (0.05\% w/v in 10

$544 \mathrm{mM}$ EDTA, $0.1 \mathrm{M}$ sodium phosphate, $\mathrm{pH} 6.5$ ) overnight at $60^{\circ} \mathrm{C} . \quad{ }^{35} \mathrm{SO}_{4}$-labeled

545 glycosaminoglycans (GAGs) were precipitated by the addition of $0.5 \%$ cetylpyridinum chloride

$546(\mathrm{CPC})$ in $0.002 \mathrm{M} \mathrm{Na}^{2} \mathrm{SO}_{4}$ in the presence of unlabeled carrier chondroitin sulfate $(1 \mathrm{mg} / \mathrm{ml}$ in

$547 \mathrm{dH}_{2} \mathrm{O}$ ). The samples were incubated for $30 \mathrm{~min}$ at $37^{\circ} \mathrm{C}$ and precipitated $\mathrm{GAGs}$ were collected on

548 Whatman filters (GF/F) using a Millipore 12-port sampling manifold as previously described

549 (Rada, McFarland et al., 1992). Radioactivity was measured directly on the filters by liquid

550 scintillation counting.

551 Statistics. Sample sizes were calculated using G*Power 3.1.9.2 using two tailed tests with an $\alpha=$

5520.05 , and an effect size determined by group means and standard deviations previously published

553 by this lab and others (Rada, Thoft et al., 1991, Wallman \& Adams, 1987. All experiments were

554 repeated at least one time, and sample sizes and results reported reflect the cumulative data for

555 all trials of each experiment. Parametric analyses between groups were made using paired or

556 unpaired Student's t-tests, and a one-way ANOVA followed by a Bonferroni correction for

557 multiple comparisons. Non-parametric analyses between groups were made using the Mann-

558 Whitney $U$ test, or the Kruskal-Wallis test for multiple comparisons (GraphPad Prism 5, La Jolla,

559 CA). Results were considered significant with $p$-value $\leq 0.05$. 


\section{Acknowledgements}

562 This work was supported by NIH grant R01EY09391 (JAS) and by NIGMS COBRE Grant

563 P30GM122744 (Ma, J-X., PI). The authors would like to thank Dr. Frederick (Kris) Miller

564 (Department of Cell Biology, University of Oklahoma Health Science Center) and Dr. Randle

565 Gallucci (Department of Pharmaceutical Sciences, University of Oklahoma Health Science Center)

566 for their helpful discussions and suggestions.

567

\section{Conflict of interest statement}

569 JAS, EMC: No competing interests declared

570

571 


\section{References}

573

574

575

576

577

578

579

580

581

582

583

584

585

586

587

588

589

590

591

592

593

594

595

596

597

598

599

600

601

602

603

604

605

606

607

608

609

610

611

612

613

614

Buch H, Vinding T, Nielsen NV (2001) Prevalence and causes of visual impairment according to World Health Organization and United States criteria in an aged, urban Scandinavian population: the Copenhagen City Eye Study. Ophthalmology 108: 2347-57

Carr BJ, Stell WK (2016) Nitric Oxide (NO) Mediates the Inhibition of Form-Deprivation Myopia by Atropine in Chicks. Sci Rep 6: 9

Chia A, Chua WH, Cheung YB, Wong WL, Lingham A, Fong A, Tan D (2012) Atropine for the treatment of childhood myopia: safety and efficacy of $0.5 \%, 0.1 \%$, and $0.01 \%$ doses (Atropine for the Treatment of Myopia 2). Ophthalmology 119: 347-54

Demirel I, Vumma R, Mohlin C, Svensson L, Save S, Persson K (2012) Nitric oxide activates IL-6 production and expression in human renal epithelial cells. Am J Nephrol 36: 524-30

Fischer AJ, Stell WK (1999) Nitric oxide synthase-containing cells in the retina, pigmented epithelium, choroid, and sclera of the chick eye. J Comp Neurol 405: 1-14

Fitzgerald ME, Wildsoet CF, Reiner A (2002) Temporal relationship of choroidal blood flow and thickness changes during recovery from form deprivation myopia in chicks. Exp Eye Res 74: 561-70

Graham B, Judge SJ (1999) The effects of spectacle wear in infancy on eye growth and refractive error in the marmoset (Callithrix jacchus). Vision Res 39: 189-206

Guan Z, Buckman SY, Pentland AP, Templeton DJ, Morrison AR (1998) Induction of cyclooxygenase-2 by the activated MEKK1 --> SEK1/MKK4 --> p38 mitogen-activated protein kinase pathway. J Biol Chem 273: 12901-8

Holden BA, Fricke TR, Wilson DA, Jong M, Naidoo KS, Sankaridurg P, Wong TY, Naduvilath TJ, Resnikoff S (2016) Global Prevalence of Myopia and High Myopia and Temporal Trends from 2000 through 2050. Ophthalmology 123: 1036-42

Howlett MH, McFadden SA (2006) Form-deprivation myopia in the guinea pig (Cavia porcellus). Vision Res 46: 267-83

Hung LF, Crawford ML, Smith EL (1995) Spectacle lenses alter eye growth and the refractive status of young monkeys. Nat Med 1: 761-5

Kishimoto T (2006) Interleukin-6: discovery of a pleiotropic cytokine. Arthritis Res Ther 8 Suppl 2: S2

Livak KJ, Schmittgen TD (2001) Analysis of relative gene expression data using real-time quantitative PCR and the 2(-Delta Delta C(T)) Method. Methods 25: 402-8

Makris AC, Sotzios Y, Zhou Z, Makropoulou M, Papapetropoulos N, Zacharatos P, Pyriochou A, Roussos C, Papapetropoulos A, Vassilakopoulos T (2010) Nitric oxide stimulates interleukin-6 production in skeletal myotubes. J Interferon Cytokine Res 30: 321-7

Marzani D, Wallman J (1997) Growth of the two layers of the chick sclera is modulated reciprocally by visual conditions. Invest Ophthalmol Vis Sci 38: 1726-39

McBrien NA, Moghaddam HO, Reeder AP (1993) Atropine reduces experimental myopia and eye enlargement via a nonaccommodative mechanism. Invest Ophthalmol Vis Sci 34: 205-15

Mertz JR, Wallman J (2000) Choroidal retinoic acid synthesis: a possible mediator between refractive error and compensatory eye growth. Exp Eye Res 70: 519-27 
Nickla DL, Damyanova P, Lytle G (2009) Inhibiting the neuronal isoform of nitric oxide synthase has similar effects on the compensatory choroidal and axial responses to myopic defocus in chicks as does the non-specific inhibitor L-NAME. Exp Eye Res 88: 1092-9

Nickla DL, Wildsoet CF (2004) The effect of the nonspecific nitric oxide synthase inhibitor NGnitro-L-arginine methyl ester on the choroidal compensatory response to myopic defocus in chickens. Optom Vis Sci 81: 111-8

Nickla DL, Wilken E, Lytle G, Yom S, Mertz J (2006) Inhibiting the transient choroidal thickening response using the nitric oxide synthase inhibitor I-NAME prevents the ameliorative effects of visual experience on ocular growth in two different visual paradigms. Exp Eye Res 83: 456-64

Norton TT, Siegwart JT, Jr., Amedo AO (2006) Effectiveness of hyperopic defocus, minimal defocus, or myopic defocus in competition with a myopiagenic stimulus in tree shrew eyes. Invest Ophthalmol Vis Sci 47: 4687-99

Pendrak K, Papastergiou GI, Lin T, Laties AM, Stone RA (2000) Choroidal vascular permeability in visually regulated eye growth. Exp Eye Res 70: 629-37

Rada JA, Hollaway, L.Y., Li, N., Napoli, J. (2012) Identification of RALDH2 as a Visually Regulated Retinoic Acid Synthesizing Enzyme in the Chick Choroid. Invest Ophthalmol Vis Sci 53: 16491662

Rada JA, McFarland AL, Cornuet PK, Hassell JR (1992) Proteoglycan synthesis by scleral chondrocytes is modulated by a vision dependent mechanism. Curr Eye Res 11: 767-82

Rada JA, Palmer L (2007) Choroidal regulation of scleral glycosaminoglycan synthesis during recovery from induced myopia. Invest Ophthalmol Vis Sci 48: 2957-66

Rada JA, Thoft RA, Hassell JR (1991) Increased aggrecan (cartilage proteoglycan) production in the sclera of myopic chicks. Dev Biol 147: 303-12

Schaeffel F, Glasser A, Howland HC (1988) Accommodation, refractive error and eye growth in chickens. Vision Res 28: 639-57

Shen W, Sivak JG (2007) Eyes of a lower vertebrate are susceptible to the visual environment. Invest Ophthalmol Vis Sci 48: 4829-37

Sherman SM, Norton TT, Casagrande VA (1977) Myopia in the lid-sutured tree shrew (Tupaia glis). Brain Res 124: 154-7

Siednienko J, Nowak J, Moynagh PN, Gorczyca WA (2011) Nitric oxide affects IL-6 expression in human peripheral blood mononuclear cells involving cGMP-dependent modulation of NFkappaB activity. Cytokine 54: 282-8

Steensberg A, van Hall G, Osada T, Sacchetti M, Saltin B, Klarlund Pedersen B (2000) Production of interleukin- 6 in contracting human skeletal muscles can account for the exercise-induced increase in plasma interleukin-6. J Physiol 529 Pt 1: 237-42

Summers JA, Harper AR, Feasley CL, Van-Der-Wel H, Byrum JN, Hermann M, West CM (2016) Identification of Apolipoprotein A-I as a Retinoic Acid-binding Protein in the Eye. J Biol Chem 291: 18991-9005

Summers Rada JA, Hollaway LR (2011) Regulation of the biphasic decline in scleral proteoglycan synthesis during the recovery from induced myopia. Exp Eye Res 92: 394-400

Troilo D, Judge SJ (1993) Ocular development and visual deprivation myopia in the common marmoset (Callithrix jacchus). Vision Res 33: 1311-24 
657 Troilo D, Smith EL, 3rd, Nickla DL, Ashby R, Tkatchenko AV, Ostrin LA, Gawne TJ, Pardue MT, 658 Summers JA, Kee CS, Schroedl F, Wahl S, Jones L (2019) IMI - Report on Experimental Models 659 of Emmetropization and Myopia. Invest Ophthalmol Vis Sci 60: M31-M88

660 Upadhyay A, Beuerman RW (2020) Biological Mechanisms of Atropine Control of Myopia. Eye Contact Lens 46: 129-135

Wallman J, Adams JI (1987) Developmental aspects of experimental myopia in chicks: susceptibility, recovery and relation to emmetropization. Vision Res 27: 1139-63

Wallman J, Turkel J, Trachtman J (1978) Extreme myopia produced by modest change in early visual experience. Science 201: 1249-51

Wallman J, Wildsoet C, Xu A, Gottlieb MD, Nickla DL, Marran L, Krebs W, Christensen AM (1995) Moving the retina: choroidal modulation of refractive state. Vision Res 35: 37-50

Wallman J, Winawer J (2004) Homeostasis of eye growth and the question of myopia. Neuron 43:

$669 \quad 447-68$

WD E (2000) Nitric oxide in the retina. Functional neuroanatomy of the nitric oxide system. In Handbook of chemical neuroanatomy, Devente J VS (ed) pp 111-145. Amsterdam: Elsevier and Eye Growth in Infant New World Monkeys. Invest Ophthalmol Vis Sci 60: 2623-2630 diseases. Pathophysiology 24: 123-131 


\section{Supplementary Figures}

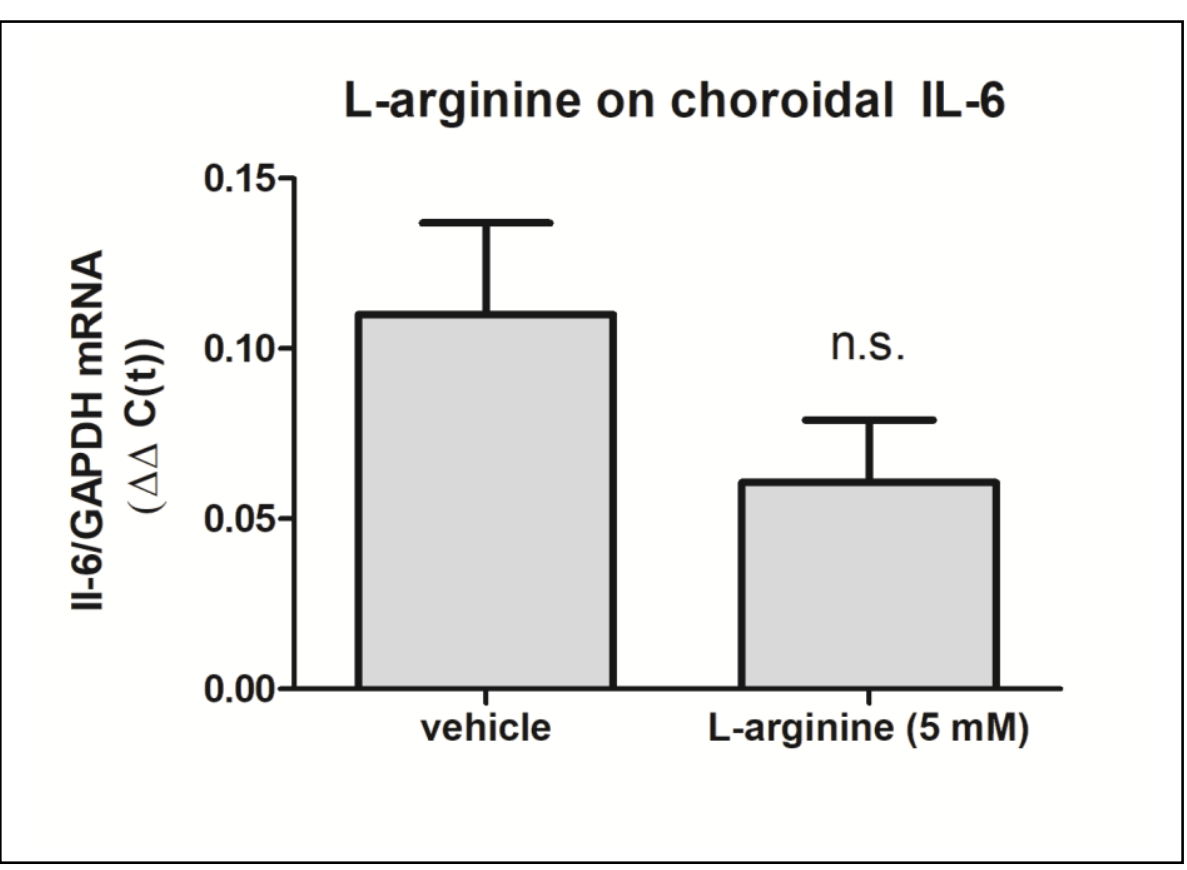

Figure S1. L-arginine does not stimulate choroidal IL-6 gene expression. Incubation of chicken choroids in organ culture with Larginine for $24 \mathrm{hrs}$ had no significant effect on choroidal IL-6 gene expression. ( $p=0.1401$, Student's t-test, $n=16$ choroids in each group). 


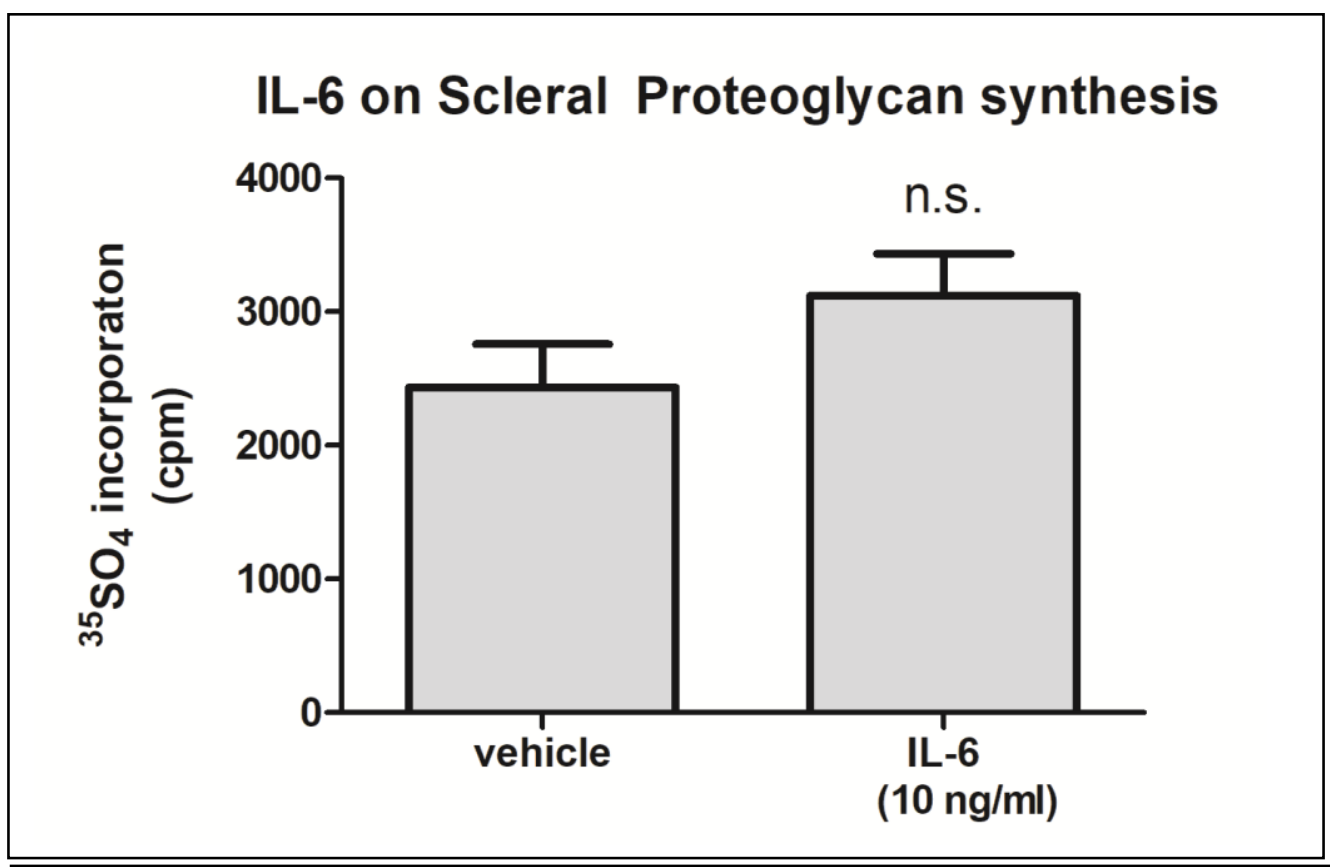

Figure S2. IL-6 has no direct effect on scleral proteoglycan synthesis. Incubation of chicken sclera in organ culture with recombinant chicken IL-6 (10 ng/ml) for $24 \mathrm{hrs}$ had no significant effect on scleral proteoglycan synthesis. ( $p=0.1439$, Student's t-test, $n=11$ sclera in each group). 